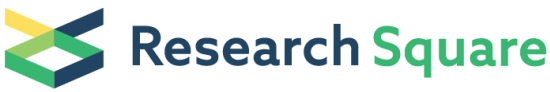 \\ Preprints are preliminary reports that have not undergone peer review. \\ They should not be considered conclusive, used to inform clinical practice, or referenced by the media as validated information.
}

\section{A Phase I Study of K-001 in Patients with Advanced Pancreatic Ductal Adenocarcinoma}

\section{Jiujie Cui}

Department of Medical Oncology, Renji Hospital, School of Medicine, Shanghai Jiaotong University https://orcid.org/00000003-0853-7569

\section{Haiyan Yang}

Department of Medical Oncology, Renji Hospital, School of Medcine, Shanghai Jiaotong University

\section{Jue Liu}

Department of Epidemiology and Biostatistics, School of Public Health, Peking University

\section{Donghui Chen}

Department of Oncology, First People's Hospital, Shanghai Jiaotong University

\section{Jiong $\mathrm{Hu}$}

Department of Medical Oncology, Renji Hospitao, School of Medicine, Shanghai Jiaotong University

\section{Haiyan Zhang}

Department of Oncology, First People's Hospital, Shanghai Jiaotong University

\section{Yu Wang}

Department of Medical Oncology, Renji Hospital, School of Medicine, Shanghai Jiaotong University

\section{Ting Han}

Department of Medical Oncology, Renji Hospital, School of Medicine, Shanghai Jiaotong University

\section{Tiebo Mao}

Department of Medical Oncology, Renji Hospital, School of Medicine, Shanghai Jiaotong Universtiy

\section{Feng Jiao}

Department of Medical Oncology, Renji Hospital, School of Medicine, Shanghai Jiaotong University

\section{Ewelina Biskup}

College of Fundamental Medicine, Shanghai University of Medicine and Health Sciences

\section{Yaotian Pan}

Institute of Psychology Chinese Academy of Sciences

Min Liu

Department of Epidemiology and Biostatistics, School of Public Health, Peking University

\section{Liwei Wang ( $\square$ wangliwei@renji.com )}

https://orcid.org/0000-0002-0031-4363

\section{Research article}

Keywords: antitumor drug, flatulence, constipation, haemorrhoids bleeding

Posted Date: April 6th, 2021

DOI: https://doi.org/10.21203/rs.3.rs-394558/v1

License: (c) (i) This work is licensed under a Creative Commons Attribution 4.0 International License. Read Full License 


\section{Abstract}

\section{Background:}

$\mathrm{K}-001$ is an oral antitumor drug made from active ingredients of marine microorganisms. The current study aimed to evaluate safety and antitumor activity of K-001 in patients with advanced pancreatic ductal adenocarcinoma (PDAC).

\section{Methods:}

In this phase I, open-label trial, patients with advanced PDAC were recruited to a dose-escalation study in a standard 3+3 design. K-001 was administered twice daily in 4-week cycles, and dose escalation from $1350 \mathrm{mg}$ to $2160 \mathrm{mg}$ twice daily was evaluated. Physical examination and laboratory tests were done at screening and then weekly. The safety, dose-limiting toxicity (DLT), and maximum tolerated dose (MTD) of K-001 were assessed, and tumor response was estimated by Response Evaluation Criteria in Solid Tumor (RECIST).

\section{Results:}

Eighteen patients with advanced PDAC were screened, and twelve eligible patients were analyzed in the study. No DLT was observed. Totally, 47 adverse events (AEs) presented, and 14 drug-related AEs were reported in 7 patients, including 8 grade 1 events (57.1\%) and 6 grade 2 events (42.9\%). There was no grade 3 or 4 drug-related AE. In these 14 drug-related AEs, the most frequent ones were dyspepsia (21.4\%), followed by flatulence, constipation, and haemorrhoids bleeding (above $10 \%$ of each). Among all 12 patients, 10 patients (83.3\%) maintained stable disease (SD), and 2 patients (16.7\%) had progressive disease (PD). The objective response rate (ORR) was $0 \%$ and the disease control rate (DCR) was $83.3 \%$.

\section{Conclusions:}

K-001 has satisfactory safety and tolerability, as well as meaningful antitumor activity in advanced PDAC patients. Further evaluation of K-001 in phase II/III appears warranted.

Trial registration: NCT02720666. Registered 28 Match 2016 - Retrospectively registered, https://clinicaltrials.gov/ct2/show/NCT02720666.

\section{Background}

Pancreatic ductal adenocarcinoma (PDAC), also called pancreatic cancer, is among the most lethal cancer types world-wide with high mortality that almost closely parallels incidence, and is chemoresistant with less than $10 \%$ response rate to standard treatment[1]. Most PDAC patients who accept surgeon will relapse within one or two years, and their 5-year survival rate is less than $5 \%$ (the data has not fluctuated significantly in the past 20 years). It has been estimated that PDAC may emerge as the second leading cause of cancer-related deaths by 2030[2]. Particularly, about $85 \%$ of PDAC patients have already developed into incurable metastatic or locally advanced stage at the time of diagnosis[3]. Thus, chemotharapy-based comprehensive treatment is essential for PDAC patients, but the options are quite limited.

Compared with the rapid development of therapies for other cancer types, the treatment of pancreatic cancer, especially pancreatic ductal adenocarcinoma (PDAC), has been lacking in clinical progress. Mutant targeting and immunological therapies have shown efficacy or promise for certain types of cancer, but have not yet achieved similar results for pancreatic cancer[4-7]. Gemcitabine (GEM) has replaced fluorouracil as the standard first-line treatment since 1997, with the primary endpoint of "clinical benefit responses" including measurements of pain, performance status, and weight[8]. The tolerance of GEM was quite well, but the efficacy was unsatisfactory with 5.65 months of median overall survival (OS) and 18\% of the 1year OS rate. Thereafter, many combinations of GEM with a variety of cytotoxic and targeted agents have been investigated, but no added benefit was observed in OS[9-14]. In 2007, Erlotinib plus GEM got a positive result statistically, but the median OS was only 6.24 months in combination group as compared with 5.91 months in GEM group[15]. In 2011, a phase III study 
showed that irinotecan, oxaliplatin, and leucovorin-modulated fluorouracil (FOLFIRINOX) significantly improved the median OS compared to GEM (11.1 months vs 6.8 months)[16]. But the toxicities, such as neutropenia, diarrhea, and peripheral neuropathy were also significantly increased in FOLFIRINOX group, limiting the widespread use of FOLFIRINOX in Asian or patients with poor performance status. In 2013, a phase III trial in Japan and Taiwan showed that S-1 was not inferiority to GEM in median OS[17]. Another blockbuster study showed that nab-paclitaxel plus GEM significantly improved the median OS and progression-free survival (PFS), with acceptable tolerance[18]. For second line therapy, nanoliposomal irinotecan in combination with fluorouracil and folinic acid prolonged the median 0S[19]. Clinical studies in recent years have exhibited some degree of progress on efficacy of PDAC, nonetheless, toxic effects and tolerance are still the major concern in the treatments, especially for patients of several line therapies, or patients with poor performance status, who are intolerable to mono or multiple chemotherapy.

It is obvious that a safe, effective, and low toxic drug is highly demanded in PDAC treatment. Existing studies have shown that antitumor drugs screened from natural products are more promising for the demand than that from synthetic ones, due to their less toxic side effects[20]. K-001 is a biological compound made from active ingredients of marine microorganisms. The main components of K-001 are peptidoglycan (PGN) and its molecular weight is more than 100,000 daltons. The preclinical studies showed that K-001 was non-toxic or slightly toxic substances. In the previous phase I study of K-001 on multiple kinds of advanced refractory solid tumors, four doses were tested $(670 \mathrm{mg}, 1350 \mathrm{mg}, 2025 \mathrm{mg}$ and $2700 \mathrm{mg}$ daily), and dose limited toxicity (DLT) was not observed. Moreover, the study showed that K-001 could improve performance status, appetite and quality of life, which are also highly demanded for PDAC. Based on those prior studies, the current study focused on the safety and antitumor activity of oral drug K-001 in patients with advanced PDAC.

\section{Methods}

The current study was a phase I, open-label, single-center, dose-escalation clinical trial to determine the dose limited toxicity (DLT), the maximum tolerated dose (MTD) and the recommended dose (RD) for phase II/III trials, as well as the preliminary antitumor effects of K-001 in patients with advanced PDAC. The study was registered with the US National Library of Medicine (ClinicalTrials.gov) as NCT02720666.

\section{Patient eligibility criteria}

The following inclusion criteria were used for participant selection: (1) aged 18-70 years; (2) histologically or cytologically confirmed locally advanced or metastatic PDAC; (3) relapsed or refractory to standard therapy; (4) above 28 days from the end of the last chemotherapy; (5) unsuitable or unwilling to standard therapy; (6) at least one measurable or assessable target lesion as defined by the Response Evaluation Criteria In Solid Tumors version 1.0 (RECIST v1.0)[21]; (7) the Eastern Cooperative Oncology Group performance status (ECOG PS) $\leq 1$; (8) life expectancy of longer than three months; (9) ability to take medications orally; (10) hematopoietic function (absolute neutrophils count $\geq 1.5 \times 10^{9} / \mathrm{L}$, hemoglobin $\geq 9.0 \mathrm{~g} / \mathrm{dL}$, platelets count $\geq 80 \times 10^{9} / \mathrm{L}$ ); (11) hepatic function (bilirubin $\leq 1.5 \times$ upper limit of normal (ULN), albumin $\geq 3.0 \mathrm{~g} / \mathrm{dL}$, alanine aminotransferase (ALT) and aspartate aminotransferase (AST) $\leq 3.0 \times$ ULN in patients without liver metastasis, or ALT and AST $\leq 5.0 \times \mathrm{ULN}$ in patients with liver metastasis); (12) renal function(serum creatinine $\leq 1.5 \times \mathrm{ULN}$, creatinine clearance rate $\geq 60 \mathrm{ml} / \mathrm{min}$ ).

Patients were excluded on criteria of (1) non-adenocarcinoma of pancreatic tumors; (2) the target lesion had been treated by radiotherapy with no progression prior to the current trial; (3) central nervous system or leptomeningeal metastases; (4) Vater's ampullary carcinoma or biliary adenocarcinoma; (5) partial or complete intestinal obstruction; (6) a history of any other malignancy within five years, excepted: a) a consecutive 5-year disease free survival from single surgery of other malignancies or b) cured cutaneous basal cell carcinoma or cured in situ carcinoma of the cervix; (7) received major surgery within 4 weeks; 8) infected with HIV, hepatitis B or hepatitis C; (9) having serious concomitant diseases.

\section{Treatment}


Using the standard $3+3$ design, this trial consisted of four escalating dose levels $(1350 \mathrm{mg}, 1620 \mathrm{mg}, 1890 \mathrm{mg}$ and $2160 \mathrm{mg}$ $B I D)$ and corresponding four cohorts $(A, B, C$, and $D)$ of three patients, with three additional candidates for each cohort as necessary. Each cohort was treated at only one dose level, and allowed to continue if patients were receiving clinical benefit. The cohort $A$ was orally administered the starting dose of K-001 twice daily for 4 weeks as a circle, then the subsequent cohorts $(B, C$ and $D)$ were treated respectively at the increasing dose levels that had been fixed in advance. Only after the observation of one dose level was completed, can the trial at next higher dose level be carried out. Two or more dose cohorts may not be administered simultaneously.

Based on previous study results, the starting dose was the maximum one of the previous study, therefore a conservative incremental percent was set up, which was lower than what the improved Fibonacci's method recommended (cohorts, dose levels and increment percents exhibited in Table 1).

Table 1

Dose level and cohort

\begin{tabular}{|lllll|}
\hline Cohort & A & B & C & D \\
\hline Incremental percent & Starting dose & $20 \%$ & $17 \%$ & $14 \%$ \\
\hline Dose level & $2700 \mathrm{mg} /$ day & $3240 \mathrm{mg} /$ day & $3780 \mathrm{mg} /$ day & $4320 \mathrm{mg} /$ day \\
& $(1350 \mathrm{mg}$ BID $)$ & $(1620 \mathrm{mg} \mathrm{BID})$ & $(1890 \mathrm{mg}$ BID $)$ & $(2160 \mathrm{mg} \mathrm{BID})$ \\
\hline Number of patient & 3 & 3 & 3 & 3 \\
\hline
\end{tabular}

Adverse events (AEs) were graded using the National Cancer Institute Common Terminology Criteria for Adverse Events version 4.0 ( $\mathrm{NCl}$ CTCAE v4.0)[22], and the relationship of AEs to the study drug was evaluated. Dose limiting toxicity (DLT) was defined as any grade $3 \mathrm{AE}$ or above that was definitely, or probably related to K-001 administration. The maximum tolerated dose (MTD) was defined as the highest dose level at which $\leq 33 \%$ of patients experience DLT[23].

If no DLT was observed, the trial escalated to the next dose cohort. If one of the three patients experienced a DLT at a certain dose level, three more patients would be administered at the same level, and patients with DLT should immediately be discontinued with medication and withdrawn from the trial; if DLT no longer presented, the trial proceeded at the next upper dose level; if DLT was still observed, the trial was closed, and all patients were followed for safety at day 28 after closure of the trial.

\section{Assessment}

Medical histories, disease characteristics and demographic data were collected at screening. The primary endpoints of this trial were safety and tolerability of the study drug, which were measured by adverse events (AEs), vital sign, electrocardiogram, and laboratory tests at baseline and on days 8, 15, 22, 29 and 56. Tumor responses were assessed using Response Evaluation Criteria in Solid Tumors (RECIST version 1.0). Imaging studies (CT or MRI) of cancer sites were done within 2 weeks prior to the enrolment and on day 29. Clinical benefit responses were also estimated such as pain index by Numerical Rating Scale (NRS), and Quality of Life (QoL) by European Organization for Research and Treatment of Cancer Quality of Life questionnaire-Core 30 version 3.0 (EORTC QLQ-C30 3.0) at baseline and on days 8, 15, 22, 29 and 56[24].

\section{Results}

The trial was conducted in First People's Hospital, School of Medicine, Shanghai Jiaotong University from February 2016 to December 2016, and the cutoff date for analysis was June 2017. The protocol was approved by the Institutional Review Board of the Hospital in accordance with the ethical principles of the Declaration of Helsinki (6th revision, 2008). All patients provided written informed consent for participation.

\section{Baseline characteristics of patients}


A total of eighteen advanced PDAC patients were screened for this study, and six of them did not meet the inclusion criteria. Twelve eligible patients were analyzed in the study and two of them did not return on the day 56 . The baseline characteristics are presented in Table 2. Median age of the twelve patients was 62 years (range, 53-67 years) and eight (67\%) of them were male. Eight patients (67\%) were on stage IV. Three patients $(25.0 \%)$ did not receive any previous chemotherapy.

Table 2

Baseline patient characteristics

\begin{tabular}{|ll|}
\hline & Number of patients (\%) \\
\hline Total & $12(100.0)$ \\
\hline Median age in years (range) & $62(53-67)$ \\
\hline Sex & $8(67.0)$ \\
\hline Male & $4(33.0)$ \\
\hline Female & \\
\hline ECOG performance status & $0(0)$ \\
\hline 0 & $12(100.0)$ \\
\hline 1 & $0(0)$ \\
\hline Tumor stage at the time of diagnosis & $1(8.3)$ \\
\hline I & $3(25.0)$ \\
\hline$\square$ & $8(66.7)$ \\
\hline$\square$ & $9(75.0)$ \\
\hline$\square$ & $3(25.0)$ \\
\hline Prior chemotherapy therapy & \\
\hline Yes & \\
\hline
\end{tabular}

\section{Safety}

During the dose escalation (1350, 1620, 1890 and 2160mg twice daily), 12 patients completed the trial and were assessable for safety. Totally, 47 adverse events were observed, including 27 grade 1 AEs (57.4\%), 17 grade 2 AEs (36.3\%) and 3 grade 3 AEs (6.4\%), and no grade $4 \mathrm{AE}$ occurred. For the three grade $3 \mathrm{AEs}$, two of them were assessed as definitely not drug-related and the third one, gastrointestinal infection, as probably not drug-related, and all of them were reversible and manageable by treatments correspondingly. Among all 47 adverse events, 14 AEs were assessed as definitely or probably drug-related, with 8 grade 1 events (57.1\%) and 6 grade 2 events (42.9\%). These 14 AEs were reported in 7 patients (Table 3), with dyspepsia $(21.4 \%)$ as the most frequent one, followed by flatulence, constipation, and haemorrhoids bleeding (above $10 \%$ of each).

Besides, the correlation between the number of AEs and the dose levels was not significant $(p=0.334,2$-tailed), indicating that AEs were not dose dependent (AEs and dose levels exhibited in Table 4). In this phase I study, no DLT of oral K-001 with grade 3 or above drug-related AE was observed in patients during the escalating treatment cycles. Therefore, the MTD of K-001can be initially defined as $1350 \mathrm{mg}$-twice-daily for subsequent phase II/III studies. 
Table 3

Drug-related adverse events occurring in any patient (\%)

\begin{tabular}{|llllll|}
\hline Toxicity & Grade 1 & Grade 2 & Grade 3 & Grade 4 & Any Grade \\
\hline Dyspepsia & $1(7.1)$ & $2(14.3)$ & 0 & 0 & $3(21.4)$ \\
\hline Flatulence & $1(7.1)$ & $1(7.1)$ & 0 & 0 & $2(14.3)$ \\
\hline Constipation & $1(7.1)$ & $1(7.1)$ & 0 & 0 & $2(14.3)$ \\
\hline Haemorrhoids bleeding & $1(7.1)$ & $1(7.1)$ & 0 & 0 & $2(14.3)$ \\
\hline Rash & 0 & $1(7.1)$ & 0 & 0 & $1(7.1)$ \\
ECG ST-T change & $1(7.1)$ & 0 & 0 & 0 & $1(7.1)$ \\
\hline Dizzy & $1(7.1)$ & 0 & 0 & 0 & $1(7.1)$ \\
\hline Diarrhea & $1(7.1)$ & 0 & 0 & 0 & $1(7.1)$ \\
\hline Nausea & $1(7.1)$ & 0 & 0 & 0 & $1(7.1)$ \\
\hline Total & $8(57.1)$ & $6(42.9)$ & 0 & 0 & $14(100.0)$ \\
\hline
\end{tabular}

Table 4

Dose level and AEs

\begin{tabular}{|llllll|}
\hline Cohort & A & B & C & D & Total \\
\hline grade 1 AE & 0 & 2 & 2 & 4 & 8 \\
\hline grade 2 AE & 1 & 1 & 4 & 0 & 6 \\
\hline Total & 1 & 3 & 6 & 4 & 14 \\
\hline
\end{tabular}

\section{Antitumor activity}

According to the RECIST 1.0 criteria, all the 12 patients were evaluable for best overall response on day 29 , and 10 patients were evaluable on day 56. Among the 12 patients, no patient presented complete response (CR) or partial response (PR), 10 patients (83.3\%) maintained stable disease (SD), and 2 patients (16.7\%) had progressive disease (PD). The objective response rate (ORR) was $0 \%$ and the 4 -week disease control rate (DCR) was $83.3 \%$ (95\% confidence interval [Cl], 56.0\%-97.0\%). The percent change in tumor size from baseline by dose cohort was shown in Table 5 . 
Summary of antitumor activity of K-001

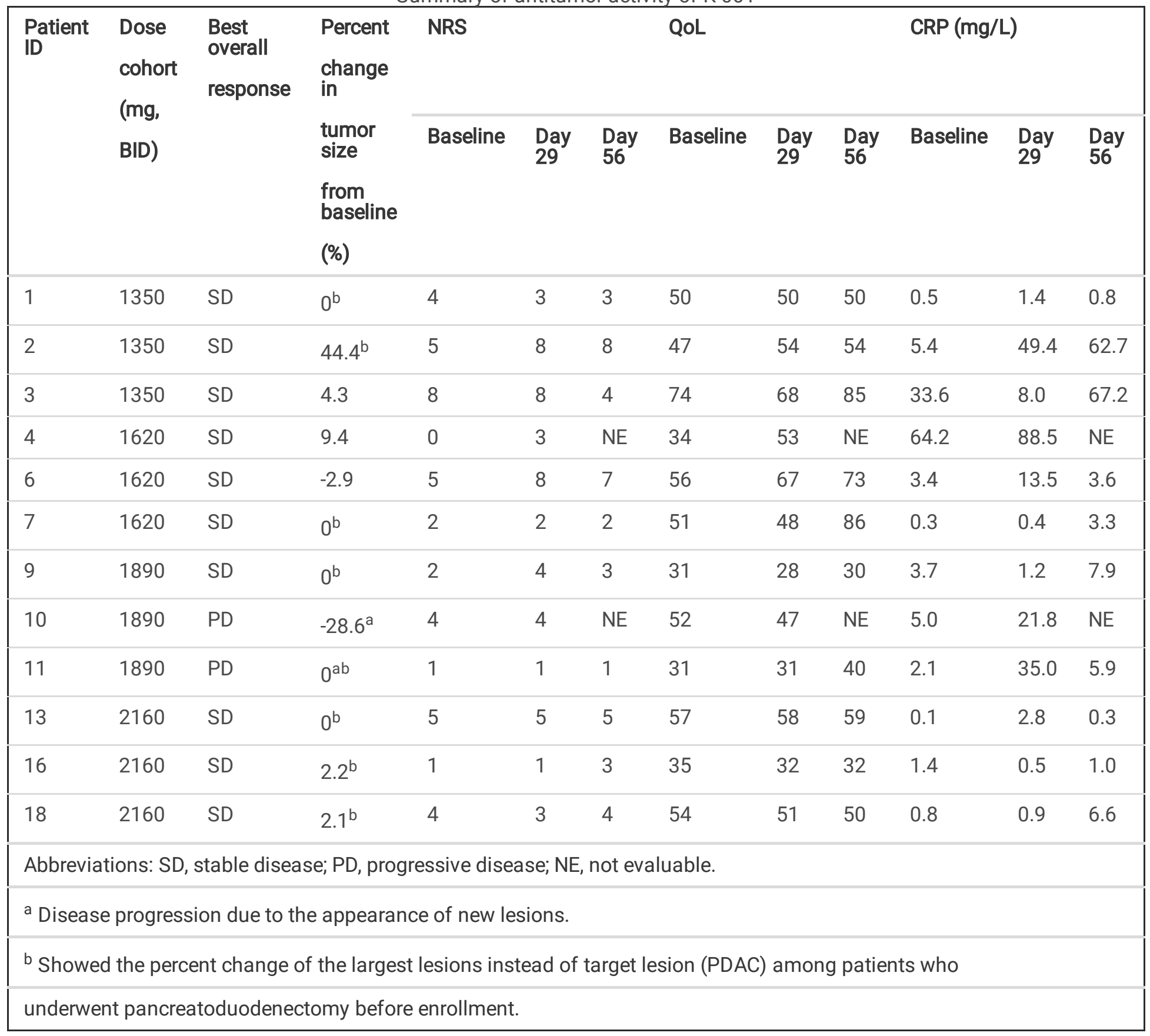

Changes of NRS score, QoL, and C-reactive protein (CRP) at baseline and on day 29, day 56 (2 patients not evaluable-16.7\%) was also shown in Table 5. Compared to their baselines, NRS scores obtained relieved or stable in 8 patients $(66.7 \%)$ on day 29 , and in 6 patients $(50.0 \%)$ on day 56 , among which 3 patients did not need to take analgesics. QoL scores kept stable or improved in 6 patients $(50.0 \%)$ on day 29 , and in 7 patients $(58.3 \%)$ on day 56 . CRP levels were decreased or stable in 3 patients $(25.0 \%)$ and increased in 9 patients $(75.0 \%)$ on day 29 , and decreased or stable in 1 patient (8.3\%) and increased in 9 patients (75.0\%). Furthermore, the results of paired samples t test (Table 6) indicated that on the whole, NRS, QoL, and CRP were increased on day 29 and day 56, compared to their baselines respectively, but did not reach the significant level. That is, NRS, QoL, and CRP remained stable during these periods. 
Table 6

Paired samples test

\begin{tabular}{|c|c|c|c|c|c|c|c|c|c|}
\hline & & \multicolumn{8}{|c|}{ Paired Differences } \\
\hline & & \multirow[t]{3}{*}{ Mean } & \multirow[t]{3}{*}{$\begin{array}{l}\text { Std. } \\
\text { Deviation }\end{array}$} & \multirow[t]{3}{*}{$\begin{array}{l}\text { Std. Error } \\
\text { Mean }\end{array}$} & \multirow{2}{*}{\multicolumn{2}{|c|}{$\begin{array}{l}95 \% \text { Confidence } \\
\text { Interval } \\
\text { of the Difference }\end{array}$}} & \multirow[t]{3}{*}{$\mathrm{t}$} & \multirow[t]{3}{*}{ df } & \multirow{3}{*}{$\begin{array}{l}\text { Sig. } \\
(2- \\
\text { tailed })\end{array}$} \\
\hline & & & & & & & & & \\
\hline & & & & & Lower & Upper & & & \\
\hline $\begin{array}{l}\text { Pair } \\
1\end{array}$ & $\begin{array}{l}\text { NRSb - } \\
\text { NRSd29 }\end{array}$ & -.750 & 1.545 & .446 & -1.732 & .232 & -1.682 & 11 & .121 \\
\hline $\begin{array}{l}\text { Pair } \\
2\end{array}$ & $\begin{array}{l}\text { QoLb - } \\
\text { QoLd29 }\end{array}$ & -1.250 & 7.448 & 2.150 & -5.982 & 3.482 & -.581 & 11 & .573 \\
\hline $\begin{array}{l}\text { Pair } \\
3\end{array}$ & $\begin{array}{l}\text { CRPb - } \\
\text { CRPd29 }\end{array}$ & -8.5750 & 18.5407 & 5.3522 & -20.3552 & 3.2052 & -1.602 & 11 & .137 \\
\hline $\begin{array}{l}\text { Pair } \\
1\end{array}$ & $\begin{array}{l}\text { NRSb - } \\
\text { NRSd56 }\end{array}$ & -.300 & 1.947 & .616 & -1.692 & 1.092 & -.487 & 9 & .638 \\
\hline $\begin{array}{l}\text { Pair } \\
2\end{array}$ & $\begin{array}{l}\text { QoLb - } \\
\text { QoLd56 }\end{array}$ & -7.300 & 11.842 & 3.745 & -15.771 & 1.171 & -1.949 & 9 & .083 \\
\hline $\begin{array}{l}\text { Pair } \\
3\end{array}$ & $\begin{array}{l}\text { CRPb - } \\
\text { CRPd56 }\end{array}$ & -10.8000 & 19.2091 & 6.0744 & -24.5414 & 2.9414 & -1.778 & 9 & .109 \\
\hline \multicolumn{10}{|c|}{ Abbreviations: NRSb, NRS baseline; QoLb, QoL baseline; CRPb, CRP baseline; NRSd29, NRS day 29; QoLd29, QoL } \\
\hline \multicolumn{10}{|c|}{ day 29; CRPd29, CRP day 29; NRSd56, NRS day 56; QoLd56, QoL day 56; CRPd56, CRP day 56.} \\
\hline
\end{tabular}

\section{Discussion}

At present, the recommended first-line treatments are mainly GEM, nab-paclitaxel, Capecitabine, S-1, 5-Fu/LV, and FOLFIRINOX[5, 8-12, 16-18]. But the proportion of those patients, who are sustainable to single drug chemotherapy, is low, and who are applicable to combined chemotherapy, is even lower. And for those with poor performance status, the treatment options are even few. Furthermore, quiet few PDAC patients could receive nanoliposomal irinotecan as second line treatment, and the third line treatments of PDAC are even deficiency[19]. Thus a safe, effective, and low toxic drug is urgently needed in PDAC.

Clinical studies in recent years have confirmed that the efficacy of FOLFIRINOX in advanced PDAC is significantly better than that of GEM. At the same time, however, the incidence of grade 3 or 4 neutropenia, febrile neutropenia, thrombocytopenia, diarrhea, and sensory neuropathy associated with the FOLFIRINOX was significantly higher than that associated with GEM. In addition, two patients even died of treatment-related factors[16]. The current study confirmed that K-001 is quite well tolerated in PDAC patients, and no dose limited toxicity (DLT) was observed in the treatment cycles. During the trial, the drug-related (definitely or probably) AEs were grade 1-2, mainly manifested as gastrointestinal reactions, and the symptoms were relieved or disappeared after appropriate treatments. All the AEs did not interfere with the dose escalation in the trial. The outcomes of the current study demonstrated that K-001 is very safe for PDAC patients.

Although efficacy was not the primary endpoint of the current trial, objective response rate (ORR), disease control rate (DCR), and other indicators of clinical benefit (NRS, QoL, and CRP) were evaluated to provide clues for subsequent phase II/III studies. In the current trial, the DCR of K-001 reached $83.3 \%(95 \% \mathrm{Cl}, 56.0 \%-97.0 \%)$, with more than $80 \%$ of the enrolled patients exhibited either tumor shrinkage or stabilization according to the RECIST 1.0 criteria (Fig. 1). In the phase III study of FOLFIRINOX versus GEM, the DCR of FOLFIRINOX was 70.2\% and of GEM was 50.9\%[16]. In MPACT trial, the DCR of Nabpaclitaxel plus GEM was $48 \%$ and of GEM was $33 \%[18]$. In GEST trial, the DCR of S- 1 was $63.3 \%$, of GEM was 62.7 and of GS 
was 71.5\%[17]. Compared with the outcome indicators of the above studies, K-001 had a quite impressive DCR for advanced PDAC patients in this trial.

Performance status (PS), measured by QoL in the trial, is one of the important prognosis indicators of PDAC patients. Weak PS is commonly accompanied with advanced PDAC patients, and results in limited options other than palliative systematic treatment[25]. Pancreatic cancer pain, measured by NRS, is associated with poor prognosis in PDAC, and is one of the main causes of decreased quality of life and survival[26]. CRP is an important aggressive marker of PDAC and its level is relevant to worse prognosis[27-29]. Paired samples t test indicated that during the trial, variations of NRS, QoL and CRP were not statistically significant, meaning that they maintained stable in the cycles of the trial. These outcomes are corresponding to DCR (SD) of $83.3 \%$, and signify that K-001 may contribute to PS improvement, have certain analgesic effect, and influence CRP level.

\section{Conclusions}

In the current phase I study, K-001 has demonstrated satisfactory safety and tolerability in the treatment of advanced PDAC patients, as well as meaningful antitumor activity in terms of DCR and clinical benefits. With the outcomes of the current trial, a multicenter, randomized and double blind phase II/III studies of K-001 has been further carried out in PDAC patients after second line treatment (ChiCTR-IIR-17013424, Chinses Clinical Trial Registry).

\section{Abbreviations}

PDAC

pancreatic ductal adenocarcinoma;DLT, dose-limiting toxicity; MTD:maximum tolerated dose; RECIST:Response Evaluation Criteria in Solid Tumor; AE:adverse event; SD:stable disease; PD:progressive disease; ORR:objective response rate; DCR:disease control rate; GEM:gemcitabine; FOLFIRINOX:irinotecan, oxaliplatin, and leucovorin-modulated fluorouracil; OS:overall survival; PFS:progression-free survival; PGN:peptidoglycan; RD:recommended dose; ECOG PS:Eastern Cooperative Oncology Group performance status; ULN:upper limit of normal; ALT:alanine aminotransferase; AST:aspartate aminotransferase; NCI CTCAE:the National Cancer Institute Common Terminology Criteria for Adverse Events; NRS:Numerical Rating Scale; QoL:Quality of Life; EORTC QLQ-C30 3.0:European Organization for Research and Treatment of Cancer Quality of Life questionnaire-Core 30 version 3.0; CR:complete response; PR:partial response; Cl:confidence interval; CRP:C-reactive protein;

\section{Declarations}

Ethics approval and consent to participate: Study protocols were approved by the Ethics Committee of First People's Hospital, Shanghai Jiaotong University (No.[2015]39). Informed consent was obtained from all patients included in this study.

Consent for publication: All authors agreed to submit for consideration for publication in this journal.

Availability of data and materials: the public data and materials could be found on line (https://clinicaltrials.gov/ct2/show/NCT02720666.)

Competing Interests: The authors declare that they have no competing interests.

Funding: The study was sponsored by Beijing Hwealth Bio-Pharmaceutical Co. Ltd.

Authors' contributions: JC, HY,DC, JH, HZ, FJ and LW designed and performed the trial; JC, HY, DC, YW, TH, TM and LW collected the clinical information; JL, YP and ML performed the data analysis; JC, HY, JL, EB, YT, ML and LW wrote the draft of the manuscript. All authors contributed to the scientific discussion of the data and of the manuscript. The authors read and approved the final manuscript. 
Acknowledgements: CONSORT checklist was not applicable for this article. This trial was a phase I study, but not a RCT.

\section{References}

1. Siegel RL, Miller KD, Jemal A: Cancer Statistics. 2017. CA: a cancer journal for clinicians 2017, 67(1):7-30.

2. Rahib L, Smith BD, Aizenberg R, Rosenzweig AB, Fleshman JM, Matrisian LM. Projecting cancer incidence and deaths to 2030: the unexpected burden of thyroid, liver, and pancreas cancers in the United States. Cancer research. 2014;74(11):2913-21.

3. Lambert A, Gavoille C, Conroy T. Current status on the place of FOLFIRINOX in metastatic pancreatic cancer and future directions. Therapeutic advances in gastroenterology. 2017;10(8):631-45.

4. Von Hoff DD, Ramanathan RK, Borad MJ, Laheru DA, Smith LS, Wood TE, Korn RL, Desai N, Trieu V, Iglesias JL, et al. Gemcitabine plus nab-paclitaxel is an active regimen in patients with advanced pancreatic cancer: a phase I/II trial. Journal of clinical oncology: official journal of the American Society of Clinical Oncology. 2011;29(34):4548-54.

5. Slamon DJ, Leyland-Jones B, Shak S, Fuchs H, Paton V, Bajamonde A, Fleming T, Eiermann W, Wolter J, Pegram M, et al. Use of chemotherapy plus a monoclonal antibody against HER2 for metastatic breast cancer that overexpresses HER2. N Engl J Med. 2001;344(11):783-92.

6. Maemondo M, Inoue A, Kobayashi K, Sugawara S, Oizumi S, Isobe H, Gemma A, Harada M, Yoshizawa H, Kinoshita I, et al. Gefitinib or chemotherapy for non-small-cell lung cancer with mutated EGFR. N Engl J Med. 2010;362(25):2380-8.

7. Brahmer JR, Tykodi SS, Chow LQ, Hwu WJ, Topalian SL, Hwu P, Drake CG, Camacho LH, Kauh J, Odunsi K, et al. Safety and activity of anti-PD-L1 antibody in patients with advanced cancer. N Engl J Med. 2012;366(26):2455-65.

8. Burris HA 3rd, Moore MJ, Andersen J, Green MR, Rothenberg ML, Modiano MR, Cripps MC, Portenoy RK, Storniolo AM, Tarassoff $\mathrm{P}$, et al. Improvements in survival and clinical benefit with gemcitabine as first-line therapy for patients with advanced pancreas cancer: a randomized trial. Journal of clinical oncology: official journal of the American Society of Clinical Oncology. 1997;15(6):2403-13.

9. Berlin JD, Catalano P, Thomas JP, Kugler JW, Haller DG, Benson AB. 3rd: Phase III study of gemcitabine in combination with fluorouracil versus gemcitabine alone in patients with advanced pancreatic carcinoma: Eastern Cooperative Oncology Group Trial E2297. Journal of clinical oncology: official journal of the American Society of Clinical Oncology. 2002;20(15):3270-5.

10. Herrmann R, Bodoky G, Ruhstaller T, Glimelius B, Bajetta E, Schüller J, Saletti P, Bauer J, Figer A, Pestalozzi B, et al. Gemcitabine plus capecitabine compared with gemcitabine alone in advanced pancreatic cancer: a randomized, multicenter, phase III trial of the Swiss Group for Clinical Cancer Research and the Central European Cooperative Oncology Group. Journal of clinical oncology: official journal of the American Society of Clinical Oncology. 2007;25(16):2212-7.

11. Louvet C, Labianca R, Hammel P, Lledo G, Zampino MG, André T, Zaniboni A, Ducreux M, Aitini E, Taïeb J, et al. Gemcitabine in combination with oxaliplatin compared with gemcitabine alone in locally advanced or metastatic pancreatic cancer: results of a GERCOR and GISCAD phase III trial. Journal of clinical oncology: official journal of the American Society of Clinical Oncology. 2005;23(15):3509-16.

12. Rocha Lima CM, Green MR, Rotche R, Miller WH Jr, Jeffrey GM, Cisar LA, Morganti A, Orlando N, Gruia G, Miller LL. Irinotecan plus gemcitabine results in no survival advantage compared with gemcitabine monotherapy in patients with locally advanced or metastatic pancreatic cancer despite increased tumor response rate. Journal of clinical oncology: official journal of the American Society of Clinical Oncology. 2004;22(18):3776-83.

13. Kindler HL, Niedzwiecki D, Hollis D, Sutherland S, Schrag D, Hurwitz H, Innocenti F, Mulcahy MF, O'Reilly E, Wozniak TF, et al. Gemcitabine plus bevacizumab compared with gemcitabine plus placebo in patients with advanced pancreatic cancer: phase III trial of the Cancer and Leukemia Group B (CALGB 80303). Journal of clinical oncology: official journal of the American Society of Clinical Oncology. 2010;28(22):3617-22. 
14. Philip PA, Benedetti J, Corless CL, Wong R, O'Reilly EM, Flynn PJ, Rowland KM, Atkins JN, Mirtsching BC, Rivkin SE, et al. Phase III study comparing gemcitabine plus cetuximab versus gemcitabine in patients with advanced pancreatic adenocarcinoma: Southwest Oncology Group-directed intergroup trial S0205. Journal of clinical oncology: official journal of the American Society of Clinical Oncology. 2010;28(22):3605-10.

15. Moore MJ, Goldstein D, Hamm J, Figer A, Hecht JR, Gallinger S, Au HJ, Murawa P, Walde D, Wolff RA, et al. Erlotinib plus gemcitabine compared with gemcitabine alone in patients with advanced pancreatic cancer: a phase III trial of the National Cancer Institute of Canada Clinical Trials Group. Journal of clinical oncology: official journal of the American Society of Clinical Oncology. 2007;25(15):1960-6.

16. Conroy T, Desseigne F, Ychou M, Bouché O, Guimbaud R, Bécouarn Y, Adenis A, Raoul JL, Gourgou-Bourgade S, de la Fouchardière $\mathrm{C}$, et al. FOLFIRINOX versus gemcitabine for metastatic pancreatic cancer. N Engl J Med. 2011;364(19):1817-25.

17. Ueno H, loka T, Ikeda M, Ohkawa S, Yanagimoto H, Boku N, Fukutomi A, Sugimori K, Baba H, Yamao K, et al. Randomized phase III study of gemcitabine plus S-1, S-1 alone, or gemcitabine alone in patients with locally advanced and metastatic pancreatic cancer in Japan and Taiwan: GEST study. Journal of clinical oncology: official journal of the American Society of Clinical Oncology. 2013;31(13):1640-8.

18. Von Hoff DD, Ervin T, Arena FP, Chiorean EG, Infante J, Moore M, Seay T, Tjulandin SA, Ma WW, Saleh MN, et al. Increased survival in pancreatic cancer with nab-paclitaxel plus gemcitabine. N Engl J Med. 2013;369(18):1691-703.

19. Wang-Gillam A, Li CP, Bodoky G, Dean A, Shan YS, Jameson G, Macarulla T, Lee KH, Cunningham D, Blanc JF, et al. Nanoliposomal irinotecan with fluorouracil and folinic acid in metastatic pancreatic cancer after previous gemcitabinebased therapy (NAPOLI-1): a global, randomised, open-label, phase 3 trial. Lancet. 2016;387(10018):545-57.

20. Karikas GA. Anticancer and chemopreventing natural products: some biochemical and therapeutic aspects. Journal of BUON: official journal of the Balkan Union of Oncology. 2010;15(4):627-38.

21. Therasse P, Arbuck SG, Eisenhauer EA, Wanders J, Kaplan RS, Rubinstein L, Verweij J, Van Glabbeke M, van Oosterom AT, Christian MC, et al. New guidelines to evaluate the response to treatment in solid tumors. European Organization for Research and Treatment of Cancer, National Cancer Institute of the United States, National Cancer Institute of Canada. J Natl Cancer Inst. 2000;92(3):205-16.

22. Institute: NC. Common Terminology Criteria for Adverse Events v4.0. http://ctep.cancer.gov/reporting/ctc.htm [Accessed 2020 January 12].

23. Le Tourneau C, Lee JJ, Siu LL. Dose escalation methods in phase I cancer clinical trials. J Natl Cancer Inst. 2009;101(10):708-20.

24. Aaronson NK, Ahmedzai S, Bergman B, Bullinger M, Cull A, Duez NJ, Filiberti A, Flechtner H, Fleishman SB, de Haes JC, et al. The European Organization for Research and Treatment of Cancer QLQ-C30: a quality-of-life instrument for use in international clinical trials in oncology. J Natl Cancer Inst. 1993;85(5):365-76.

25. Wong SS, Hsu FC, Avis NE, Clark CJ. Health-related quality of life and medical comorbidities in older patients with pancreatic adenocarcinoma: An analysis using the 1998-2011 surveillance, epidemiology, and end results-medicare health outcomes survey data. Journal of geriatric oncology. 2020;11(4):633-9.

26. Ceyhan GO, Bergmann F, Kadihasanoglu M, Altintas B, Demir IE, Hinz U, Müller MW, Giese T, Büchler MW, Giese NA, et al. Pancreatic neuropathy and neuropathic pain-a comprehensive pathomorphological study of 546 cases.

Gastroenterology. 2009;136(1):177-86.e171.

27. Mahmoud FA, Rivera NI. The role of C-reactive protein as a prognostic indicator in advanced cancer. Current oncology reports. 2002;4(3):250-5.

28. Mitsunaga S, Ikeda M, Shimizu S, Ohno I, Takahashi H, Okuyama H, Ueno H, Morizane C, Kondo S, Sakamoto Y, et al. CReactive Protein Level Is an Indicator of the Aggressiveness of Advanced Pancreatic Cancer. Pancreas. 2016;45(1):1106. 
29. Haas M, Laubender RP, Stieber P, Holdenrieder S, Bruns CJ, Wilkowski R, Mansmann U, Heinemann V, Boeck S. Prognostic relevance of CA 19 - 9, CEA, CRP, and LDH kinetics in patients treated with palliative second-line therapy for advanced pancreatic cancer. Tumour biology: the journal of the International Society for Oncodevelopmental Biology Medicine. 2010;31(4):351-7.

\section{Figures}

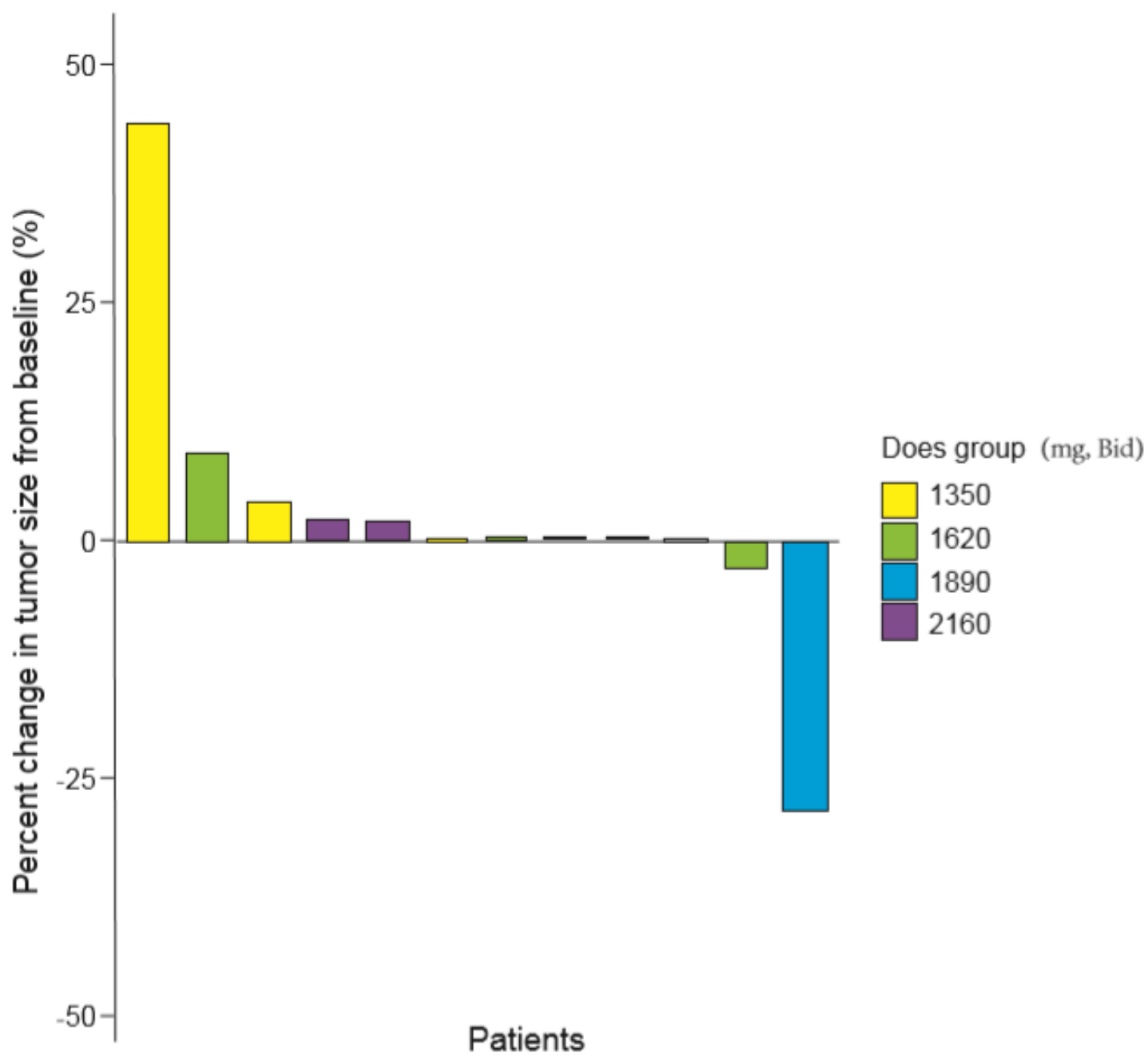

Figure 1

Waterfall plot of percent change in tumor size from baseline by dose group 